\title{
Association between dopamine D2 receptor gene polymorphisms and the risk of heroin dependence
}

\author{
N. Wang ${ }^{1 *}$, J.B. Zhang ${ }^{1 *}$, J. Zhao ${ }^{1}$, X.T. Cai ${ }^{1}$, Y.S. Zhu ${ }^{1,2}$ and S.B. Li ${ }^{1,2}$ \\ ${ }^{1}$ College of Forensic Science, Xi' an Jiaotong University, Xi'an, Shannxi, China \\ ${ }^{2}$ Key Laboratory of Ministry of Public Health for Forensic Science, Xi'an, \\ Shannxi, China \\ *These authors contributed equally to this study. \\ Corresponding author: S.B. Li \\ E-mail: shengbinli_xjtu@126.com
}

Genet. Mol. Res. 15 (4): gmr15048772

Received May 10, 2016

Accepted July 11, 2016

Published November 3, 2016

DOI http://dx.doi.org/10.4238/gmr15048772

Copyright (C) 2016 The Authors. This is an open-access article distributed under the terms of the Creative Commons Attribution ShareAlike (CC BY-SA) 4.0 License.

\begin{abstract}
Heroin dependence is a chronic relapsing brain disease. Researchers have reported that the dopamine D2 receptor (DRD2) is involved in the development of opiate dependence. To identify markers that contribute to the genetic susceptibility to heroin addiction, we examined the potential association between heroin dependence and six polymorphisms of the DRD2 gene using the MassARRAY system. Three hundred and thirty-four patients with heroin dependence and 299 healthy controls participated in the research. Compared with the healthy controls, heroin-dependent patients had a significantly lower frequency of the $A A$ genotype of rs6275 $(\mathrm{P}=0.038)$, and a significantly higher frequency of the $C$ allele of rs $1125394(\mathrm{P}=0.030)$. Statistically significant differences were observed in the genotypic and allelic frequencies of $\operatorname{rs} 17115583(\mathrm{P}=0.005$ and $\mathrm{P}=0.001$, respectively) and
\end{abstract}


rs1079597 ( $\mathrm{P}=0.03$ and $\mathrm{P}=0.02$, respectively). Haplotype analysis revealed that the $T-G-A$ (block 1) haplotype of the $D R D 2$ gene conferred a protective effect $(\mathrm{P}=0.020)$. These findings point to a role for $D R D 2$ polymorphism in heroin dependence in the Chinese Han population, and may be informative for future genetic or neurobiological studies on heroin dependence.

Key words: Heroin dependence; Dopamine D2 receptor; Single nucleotide polymorphism; Chinese Han population

\section{INTRODUCTION}

Heroin dependence is a chronic relapsing brain disease characterized by drug dependence, tolerance, and compulsive seeking and use, despite the harmful consequences (van den Bree et al., 1998; Liu et al., 2015). By the end of 2014, the number of heroin and other opiate abusers had risen to 1.46 million, accounting for $49.3 \%$ of the registered drug abusers in China. It is broadly accepted that multiple genetic and environmental risk factors and their interactions contribute to the development of drug addiction (van den Bree et al., 1998; Vereczkei et al., 2013). The authors of a previous study reported that the inherited risk of drug addiction ranged from 40 to $60 \%$ (Uhl et al., 2008). Therefore, identification of the genes that cause vulnerability to heroin dependence is urgently required.

The dopaminergic system is involved in the development of the rewarding effect, which plays a key role in drug dependence. Dopamine (DA) is one of the major neurotransmitters and has a variety of functions; it is involved in motor coordination, emotions, memory, the reward mechanism, and neuroendocrine regulation. DA exerts its effects through five DA receptors that are subdivided into two families: the D1-like DA receptors (D1 and D5) and the D2-like receptors (D2, D3, and D4) (Rangel-Barajas et al., 2015). Studies indicate that DA D2 receptor $(D R D 2)$ is closely related to the pathogenesis of drug dependence (Gorwood et al., 2012). Administration of DRD2 agonists R-(-)-propylnorapomorphine and quinpirole produced a leftward shift in the heroin dose-response function in rhesus monkeys trained to self-administer heroin under a progressive-ratio schedule of reinforcement (Rowlett et al., 2007). DRD2 knockout mice displayed a diminished reward response to opiates (Maldonado et al., 1997), and a decrease in DRD2 availability may represent a vulnerability factor for addictive disorders (Gorwood et al., 2012).

The locus of the DRD2 gene is 11q23 and it contains eight exons separated by several introns. Single nucleotide polymorphisms (SNPs) in the DRD2 gene have been reported to affect the response to psychiatric drugs. Moyer et al. (2011) found that polymorphisms in the intronic region can affect alternative splicing of the human dopamine D2 receptor and are associated with cocaine abuse. The -141delC allele (rs1799732), located near the 5' end of $D R D 2$, is associated with significantly less promoter activity and consequently affects gene expression (Parsian et al., 2000). Chen et al. (2011) reported that rs1799732 was a risk factor for heroin dependence, but other study found an opposite result. The rs1079597 SNP in the intron 1 region of $D R D 2$ affected susceptibility to smoking in young Taiwanese men (Huang et al., 2015) and susceptibility to alcohol dependency in Indian males (Prasad et al., 2010). The rs6275 SNP, which is located in exon 6, is associated with alcohol dependence (Meyers et al., 2013) and schizophrenia (Gupta et al., 2009).

Genetics and Molecular Research 15 (4): gmr15048772 
Although the roles of $D R D 2$ have been explored in many studies, the results are not consistent. Moreover, many SNPs within the gene, such as rs7350522 and rs17115583, have not yet been studied in the context of heroin dependence. Therefore, we used a larger sample size to investigate the association between six SNPs (rs1079597, rs1125394, rs17115583, rs1799732, rs6275, and rs7350522) in the DRD2 gene and the risk of heroin dependence in the Chinese Han population.

\section{SUBJECTS AND METHODS}

\section{Subjects}

The 334 subjects with heroin dependence were recruited from the Methadone Maintenance Treatment Program of the Xi'an Mental Health Center between September 2013 and May 2015. All were males with a mean age of $46.2 \pm 9.4$ years. The diagnosis of heroin dependence accorded with the DSM-IV criteria, the urine test results, and the interview responses, and a senior physician took part in the diagnosis process. Participants who fulfilled any of the following conditions were excluded: 1) abused other drugs; 2) had other mental diseases; 3) participated in other clinical trials; or 4) suffered from severe liver or kidney impairment.

The 299 control group members underwent health examinations at the Health Examination Center of the First Hospital Affiliated to the Medical College of Xi' an, Jiao Tong University. All were males with a mean age of $48.2 \pm 11.6$ years. Participants were excluded if they had a history of substance abuse, had participated in other research, or suffered from chronic brain diseases.

All participants were Han Chinese from Shannxi Province and were not genetically related. Written informed consent was obtained from all participants. The study was approved by the Ethical Committee of Xi'an, China.

\section{SNP genotyping}

Peripheral blood (3-5 mL) was collected using tubes coated with ethylenediaminetetraacetic acid (EDTA) and stored at $-80^{\circ} \mathrm{C}$. Genome DNA was extracted using an EZNA ${ }^{\mathrm{TM}}$ Blood DNA Midi Kit (Omega Bio-Tek, Norcross, GA, USA), according to the manufacturer instructions. DNA was stored at $-80^{\circ} \mathrm{C}$ for SNP analysis. Genotyping was carried out on a MassARRAY platform (Sequenom, San Diego, CA, USA). The target fragments were augmented by polymerase chain reaction (PCR). All the products were treated with shrimp alkaline phosphatase. Single nucleotide extension was then carried out using iPLEX enzyme (Sequenom). The samples were spotted onto a 384-well spectroCHIP nanodispenser (Sequenom) and analyzed using the matrix-assisted laser desorption/ionization time-of-flight (MALDI-TOF) MassARRAY system in the fully automated mode. Genotypes were automatically identified using SpectroTYPER software (Sequenom).

\section{Statistical analysis}

Hardy-Weinberg equilibrium and associations between heroin dependence and each polymorphism were assessed using the Pearson chi-square test or the Fisher exact test. Binary logistic regression was used to calculate the odds ratio (OR) and $95 \%$ confidence interval

Genetics and Molecular Research 15 (4): gmr15048772 
$(95 \% \mathrm{CI})$ in independent association between each locus and the presence of heroin dependence. The pair-wise linkage disequilibrium (LD) structure was based on D' and $\mathrm{r}^{2}$ values (D' $>0.9$, $\mathrm{r}^{2}>0.8$ ), and haplotype frequencies were constructed using the Haploview software Ver. 4.0 to construct haplotype blocks. The significance of any haplotypic association was evaluated using a likelihood ratio test. The Bonferroni correction was used in multiple testing, and the $\mathrm{P}$ value was divided by the total number of loci or haplotypes.

\section{RESULTS}

The genotypic and allelic frequencies of $D R D 2$ polymorphisms were all in agreement with the Hardy-Weinberg equilibrium. The distribution of genotype and allele frequencies and the statistical analysis of the six SNPs are described in Table 1.

\begin{tabular}{|c|c|c|c|c|c|c|c|c|c|}
\hline \multirow[t]{2}{*}{ Variable/Chromosome position } & \multirow[t]{2}{*}{ Location } & \multirow[t]{2}{*}{ MAF } & \multicolumn{2}{|c|}{ Heroin $(\mathrm{N}=334)$} & \multicolumn{2}{|c|}{ Controls $(\mathrm{N}=299)$} & \multirow[t]{2}{*}{$\mathrm{P}^{\mathrm{a}}$} & \multirow[t]{2}{*}{$\mathrm{P}^{\mathrm{b}}$} & \multirow[t]{2}{*}{$\mathrm{OR}, 95 \% \mathrm{CI}$} \\
\hline & & & $\mathrm{N}$ & $\%$ & $\mathrm{~N}$ & $\%$ & & & \\
\hline rs 1079597/113425564 & Intron 1 & 0.396 & & & & & 0.623 & 0.060 & \\
\hline $\mathrm{CC}$ & & & 96 & $28.7 \%$ & 111 & $37.1 \%$ & & 0.030 & $0.690,0.493-0.964$ \\
\hline TC & & & 168 & $50.3 \%$ & 139 & $46.5 \%$ & & 0.400 & $1.144,0.836-1.567$ \\
\hline TT & & & 70 & $21.0 \%$ & 49 & $16.4 \%$ & & 0.125 & $1.374,0.916-2.062$ \\
\hline C allele & & & 360 & $53.9 \%$ & 361 & $60.4 \%$ & & 0.020 & $0.767,0.614-0.960$ \\
\hline $\mathrm{T}$ allele & & & 308 & $46.1 \%$ & 237 & $39.6 \%$ & & & \\
\hline rs1125394/113426463 & Intron 1 & 0.408 & & & & & 0.958 & 0.086 & \\
\hline TT & & & 92 & $27.5 \%$ & 105 & $35.1 \%$ & & 0.050 & $0.712,0.507-1.000$ \\
\hline TC & & & 171 & $51.2 \%$ & 144 & $48.2 \%$ & & 0.540 & $1.103,0.806-1.510$ \\
\hline $\mathrm{CC}$ & & & 71 & $21.3 \%$ & 50 & $16.7 \%$ & & 0.127 & $1.369,0.915-2.050$ \\
\hline T allele & & & 355 & $53.1 \%$ & 354 & $59.2 \%$ & & 0.030 & $0.782,0.626-0.977$ \\
\hline C allele & & & 313 & $46.9 \%$ & 244 & $40.8 \%$ & & & \\
\hline rs17115583/113438180 & Intron 1 & 0.477 & & & & & 0.364 & 0.003 & \\
\hline GG & & & 122 & $36.6 \%$ & 78 & $26.1 \%$ & & 0.005 & $1.635,1.161-2.303$ \\
\hline GA & & & 166 & $49.8 \%$ & 157 & $52.5 \%$ & & 0.496 & $0.897,0.655-1.228$ \\
\hline $\mathrm{AA}$ & & & 45 & $13.5 \%$ & 64 & $21.4 \%$ & & 0.011 & $0.578,0.380-0.880$ \\
\hline G allele & & & 410 & $61.6 \%$ & 313 & $52.3 \%$ & & 0.001 & $1.458,1.166-1.824$ \\
\hline A allele & & & 256 & $38.4 \%$ & 285 & $47.7 \%$ & & & \\
\hline rs1799732/113475529 & $5^{\prime}$ near & 0.086 & & & & & 0.405 & 0.351 & \\
\hline $\mathrm{II}^{\mathrm{c}}$ & & & 244 & $79.2 \%$ & 219 & $83.9 \%$ & & 0.324 & $0.803,0.519-1.242$ \\
\hline $\mathrm{ID}^{\mathrm{d}}$ & & & 60 & $19.5 \%$ & 39 & $14.9 \%$ & & 0.338 & $1.245,0.795-1.950$ \\
\hline $\mathrm{DD}$ & & & 4 & $1.3 \%$ & 3 & $1.1 \%$ & & 0.855 & $1.152,0.253-5.241$ \\
\hline I allele & & & 548 & $89.0 \%$ & 477 & $91.4 \%$ & & 0.174 & $0.760,0.512-1.130$ \\
\hline D allele & & & 68 & $11.0 \%$ & 45 & $8.6 \%$ & & & \\
\hline rs6275/113412755 & Exon 6 & 0.428 & & & & & 0.603 & 0.033 & \\
\hline $\mathrm{AA}$ & & & 87 & $26.0 \%$ & 100 & $33.4 \%$ & & 0.038 & $0.694,0.492-0.979$ \\
\hline GA & & & 193 & $57.8 \%$ & 142 & $47.5 \%$ & & 0.011 & $1.506,1.098-2.064$ \\
\hline GG & & & 54 & $16.2 \%$ & 57 & $19.1 \%$ & & 0.400 & $0.838,0.555-1.265$ \\
\hline A allele & & & 367 & $54.9 \%$ & 342 & $57.2 \%$ & & 0.421 & $0.913,0.731-1.140$ \\
\hline G allele & & & 301 & $45.1 \%$ & 256 & $42.8 \%$ & & & \\
\hline rs7350522/113434481 & Intron 1 & 0.371 & & & & & 0.959 & 0.144 & \\
\hline GG & & & 109 & $32.6 \%$ & 118 & $39.5 \%$ & & 0.088 & $0.752,0.542-1.043$ \\
\hline TG & & & 166 & $49.7 \%$ & 140 & $46.8 \%$ & & 0.572 & $1.095,0.799-1.499$ \\
\hline TT & & & 59 & $17.7 \%$ & 41 & $13.7 \%$ & & 0.142 & $1.386,0.897-2.143$ \\
\hline G allele & & & 384 & $57.5 \%$ & 376 & $62.9 \%$ & & 0.051 & $0.798,0.637-1.001$ \\
\hline $\mathrm{T}$ allele & & & 284 & $42.5 \%$ & 222 & $37.1 \%$ & & & \\
\hline
\end{tabular}

MAF: minor allele frequency in controls. ${ }^{\text {P }}$ value for Hardy-Weinberg equilibrium in controls. ${ }^{b} \mathrm{P}$ value for genotype frequency and allele frequency difference. Alpha value was adjusted by the Bonferroni correction and statistically significant results $(\mathrm{P}<0.008)$. 'I refers to "Insert". 'D refers to "Delete".

Compared with the healthy controls, the heroin-dependent subjects had a significantly lower frequency of the $A A$ genotype $(\mathrm{P}=0.011, \mathrm{OR}=0.578,95 \% \mathrm{CI}=0.380-0.880$, Table 1$)$, and a significantly lower frequency of the $A$ allele $\left(\chi^{2}=10.942, \mathrm{P}=0.001, \mathrm{OR}=1.458,95 \% \mathrm{CI}\right.$

Genetics and Molecular Research 15 (4): gmr15048772 
$=1.166-1.824 ;$ Table 1) of rs 17115583, and these differences retained statistical significance after the Bonferroni correction $(\alpha=0.008)$. With regards to rs6275, there was a significant difference between the heroin-dependent subjects and the healthy controls $\left(\chi^{2}=6.835, \mathrm{P}\right.$ $=0.033$; Table 1). The frequency of the $A A$ genotype in the heroin-dependent subjects was significantly lower than in the controls $(\mathrm{P}=0.038, \mathrm{OR}=0.694,95 \% \mathrm{CI}=0.492-0.979$; Table 1). The frequency of the $C$ allele of rs 1125394 in heroin-dependent subjects was higher than in the controls $\left(\chi^{2}=4.693, \mathrm{P}=0.030, \mathrm{OR}=0.782,95 \% \mathrm{CI}=0.626-0.977\right.$; Table 1$)$. The rs $1079597 C C$ genotype $(\mathrm{P}=0.030, \mathrm{OR}=0.690,95 \% \mathrm{CI}=0.493-0.964$; Table 1$)$ and $C$ allele $\left(\chi^{2}=5.397, \mathrm{P}=0.020, \mathrm{OR}=0.767,95 \% \mathrm{CI}=0.614-0.960\right.$; Table 1$)$ were significantly less frequent in the heroin-dependent subjects compared with the controls.

The analyses of pairwise LD in the patient and control groups revealed that three SNPs (rs1125394, rs7350522, and rs17115583) were located in haplotype block 1 (D'>0.9, $\mathrm{r}^{2}>0.8$; Figure 1). The haplotype frequency of $T-G-A$ in heroin-dependent subjects was lower than in the controls $\left(\chi^{2}=5.422, \mathrm{P}=0.020, \mathrm{OR}=0.687,95 \% \mathrm{CI}=0.501-0.943\right.$; Table 2$)$.

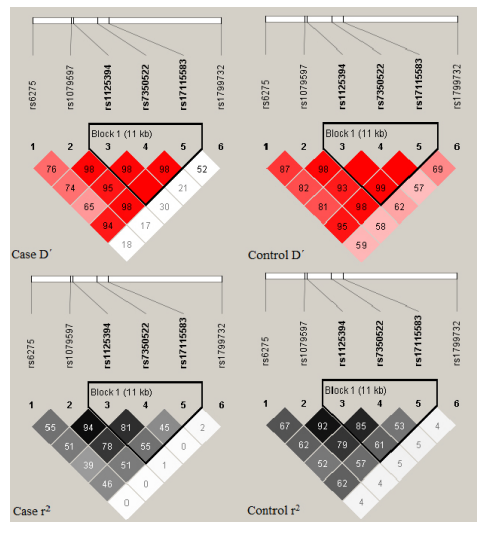

Figure 1. Linkage disequilibrium (LD) plot of the six single nucleotide polymorphisms (SNPs) in the DRD2 gene in cases (left) and controls (right). Values in squares are the pairwise calculation of D' (above) or r ${ }^{2}$ (below). Empty squares indicate $\mathrm{D}^{\prime}=1$ (i.e., complete LD between a pair of SNPs). Black squares indicate $\mathrm{r}^{2}=1$ (i.e., perfect LD between a pair of SNPs).

Table 2. DRD2 haplotype in block 1 frequencies and the results of their associations with risk of heroin dependence.

\begin{tabular}{l|c|c|c|c|c|c}
\hline Haplotype & Cases (N, \%) & Controls (N, \%) & \multicolumn{3}{|c}{ Statistics } \\
\cline { 4 - 7 } & & & $\chi^{2}$ & $\mathrm{P}^{\mathrm{a}}$ & OR & $95 \% \mathrm{CI}$ \\
\hline TGA & $128(38.323)$ & $142(47.492)$ & 5.422 & 0.020 & 0.687 & $0.501-0.943$ \\
\hline CTG & $141(42.216)$ & $111(37.124)$ & 1.707 & 0.191 & 1.237 & $0.899-1.703$ \\
\hline TGG & $49(14.671)$ & $35(11.706)$ & 1.205 & 0.272 & 1.297 & $0.815-2.064$ \\
\hline CGG & $16(4.790)$ & $11(3.679)$ & 0.477 & 0.490 & 1.317 & $0.601-2.885$ \\
\hline
\end{tabular}

${ }^{a}$ Alpha value was adjusted by the Bonferroni correction and statistically significant results $(\mathrm{P}<0.0125)$.

\section{DISCUSSION}

The $D R D 2$ gene encodes a major functional presynaptic autoreceptor that controls phasic DA neuron activity and exerts negative control on the mesolimbic dopaminergic

Genetics and Molecular Research 15 (4): gmr15048772 
pathway. Opioids can indirectly relieve this negative control by inhibiting the neurons, thereby mediating the rewarding effects of opioid dependence (Hou and Li, 2009). Several polymorphisms have a significant association with heroin dependence, e.g., rs1076560 (Clarke et al., 2014), rs1800497 (Teh et al., 2012), and rs2075654 (Al-Eitan et al., 2012). DRD2 may be a major candidate gene for heroin dependence in the Chinese Han population.

In this study, we evaluated the association between six DRD2 SNPs and heroin dependence. Four of those SNPs (rs1079597, rs17115583, rs1125394, and rs7350522) are located within intron 1. Polymorphisms in the intron region of the human dopamine D2 receptor gene can cause different structural folds in the mRNA. This changes its secondary structure, which may affect its stability and processing, thereby altering splicing and transcription (Duan et al., 2003; Zhang et al., 2007), and further modulating the expression of the DRD2 gene (Doehring et al., 2009; Zhang et al., 2010; Moyer et al., 2011). The most significant difference between heroin-dependent subjects and healthy controls was found in rs 17115583: the $G$ allele of rs 17115583 was strongly associated with an increased risk of heroin dependence. To the best of our knowledge, this is the first report to identify a significant association between rs 17115583 and heroin dependence. With regard to rs 1125394, the heroin-dependent subjects had more $C$ alleles than the controls. Furthermore, rs1125394 and rs17115583 were in strong LD (block 1), and the haplotype frequency of $T-A$ in the heroin-dependent group was lower than in the controls. The authors of a previous study reported that the $C$ allele of rs 1125394 is significantly associated with heroin dependence in Jordanians of Arab descent (Al-Eitan et al., 2012). Our results agreed with their finding. Compared with the $C$ allele, the $T$ allele of rs1125394 is associated with better response to clozapine in African-American schizophrenics than in Caucasian schizophrenics (Hwang et al., 2005), which may be caused by ethnic differences.

Caucasians with the rs $1079597 T$ allele (TaqIB1 allele) had significantly fewer binding sites (Ritchie and Noble, 2003) and a lower density of dopamine D2 receptors than subjects without it (Jönsson et al., 1999). Wang et al. (1997) found that expression of DRD2 in opiatedependent subjects decreased compared with the controls. There was a higher frequency of the $T$ allele in the heroin-dependent group in our study, which suggests that the $T$ allele of rs 1079597 contributes to the risk of heroin dependence. This finding is consistent with previous reports (Xu et al., 2004; Vereczkei et al., 2013).

$D R D 2$ rs6275 has a significant association with heroin dependence. Subjects with the $A A$ genotype had a lower frequency of heroin dependence. This indicates that rs6275 $A A$ carriers are less prone to heroin addiction. Rs6275, a His313 synonymous polymorphism in exon 6 of the $D R D 2$ gene, was previously reported to have a modest association with disease susceptibility in the Indian population (Kukreti et al., 2006), and has been reported as a variant that modulates methadone treatment (Doehring et al., 2009). Methadone is an effective drug for the treatment of opioid dependence. However, the therapeutic success rate is dependent on personalized approaches to methadone maintenance based on genetics. There is evidence of a strong correlation between bias in synonymous codon usage and the level of gene expression with the rs6275 SNP (Iida and Akashi, 2000). The minor $T$ allele of rs6275 is located near to the synonymous rs6277 SNP (Pro319Pro), which causes altered mRNA folding, decreased mRNA stability and protein synthesis, and decreased dopamine-induced upregulation of D2 receptor expression (Duan et al., 2003). Considering the linkage between rs6275 and rs6277, the molecular mechanism by which they act might be the same (Doehring et al., 2009).

We further investigated the interaction between polymorphisms and observed strong LD. The haplotype frequency of $T-G-A$ in heroin-dependent subjects was lower than that in

Genetics and Molecular Research 15 (4): gmr15048772 
the controls, which revealed that the $T-G-A$ (block 1) haplotypes of the $D R D 2$ gene displayed a protective effect, and that people with $T-G-A$ haplotypes were less prone to heroin addiction.

In conclusion, these findings will encourage future studies aimed at identifying functional polymorphisms within or close to the DRD2 gene using a systemic approach in a larger sample set. Our results agree with the dopamine hypothesis developed to understand the chronic effects of heroin on the brain. This study will improve our understanding of the neurobiological mechanisms of heroin.

\section{Conflicts of interest}

The authors declare no conflict of interest.

\section{ACKNOWLEDGMENTS}

Research partially supported by the National Science Foundation of China (\#NSFC31100900).

\section{REFERENCES}

Al-Eitan LN, Jaradat SA, Hulse GK and Tay GK (2012). Custom genotyping for substance addiction susceptibility genes in Jordanians of Arab descent. BMC Res. Notes 5: 497. http://dx.doi.org/10.1186/1756-0500-5-497

Chen D, Liu F, Shang Q, Song X, et al. (2011). Association between polymorphisms of DRD2 and DRD4 and opioid dependence: evidence from the current studies. Am. J. Med. Genet. B. Neuropsychiatr. Genet. 156B: 661-670. http:// dx.doi.org/10.1002/ajmg.b.31208

Clarke TK, Weiss AR, Ferarro TN, Kampman KM, et al. (2014). The dopamine receptor D2 (DRD2) SNP rs1076560 is associated with opioid addiction. Ann. Hum. Genet. 78: 33-39. http://dx.doi.org/10.1111/ahg.12046

Doehring A, Hentig Nv, Graff J, Salamat S, et al. (2009). Genetic variants altering dopamine D2 receptor expression or function modulate the risk of opiate addiction and the dosage requirements of methadone substitution. Pharmacogenet. Genomics 19: 407-414.http://dx.doi.org/10.1097/FPC.0b013e328320a3fd

Duan J, Wainwright MS, Comeron JM, Saitou N, et al. (2003). Synonymous mutations in the human dopamine receptor D2 (DRD2) affect mRNA stability and synthesis of the receptor. Hum. Mol. Genet. 12: 205-216. http://dx.doi. org $/ 10.1093 / \mathrm{hmg} / \mathrm{ddg} 055$

Gorwood P, Le Strat Y, Ramoz N, Dubertret C, et al. (2012). Genetics of dopamine receptors and drug addiction. Hum. Genet. 131: 803-822.http://dx.doi.org/10.1007/s00439-012-1145-7

Gupta M, Chauhan C, Bhatnagar P, Gupta S, et al. (2009). Genetic susceptibility to schizophrenia: role of dopaminergic pathway gene polymorphisms. Pharmacogenomics 10: 277-291. http://dx.doi.org/10.2217/14622416.10.2.277

Hou QF and Li SB (2009). Potential association of DRD2 and DAT1 genetic variation with heroin dependence. Neurosci. Lett. 464: 127-130.http://dx.doi.org/10.1016/j.neulet.2009.08.004

Huang CL, Ou WC, Chen PL, Liu CN, et al. (2015). Effects of interaction between dopamine D2 receptor and monoamine oxidase A genes on smoking status in young men. Biol. Res. Nurs. 17: 422-428. http://dx.doi. org/10.1177/1099800415589366

Hwang R, Shinkai T, De Luca V, Müller DJ, et al. (2005). Association study of 12 polymorphisms spanning the dopamine $\mathrm{D}(2)$ receptor gene and clozapine treatment response in two treatment refractory/intolerant populations. Psychopharmacology (Berl.) 181: 179-187. http://dx.doi.org/10.1007/s00213-005-2223-5

Iida $\mathrm{K}$ and Akashi $\mathrm{H}$ (2000). A test of translational selection at 'silent' sites in the human genome: base composition comparisons in alternatively spliced genes. Gene 261: 93-105. http://dx.doi.org/10.1016/S0378-1119(00)00482-0

Jönsson EG, Nöthen MM, Grünhage F, Farde L, et al. (1999). Polymorphisms in the dopamine D2 receptor gene and their relationships to striatal dopamine receptor density of healthy volunteers. Mol. Psychiatry 4: 290-296. http://dx.doi. org/10.1038/sj.mp.4000532

Kukreti R, Tripathi S, Bhatnagar P, Gupta S, et al. (2006). Association of DRD2 gene variant with schizophrenia. Neurosci. Lett. 392: 68-71.http://dx.doi.org/10.1016/j.neulet.2005.08.059

Genetics and Molecular Research 15 (4): gmr15048772 
Liu JH, Zhong HJ, Dang J, Peng L, et al. (2015). Single-nucleotide polymorphisms in dopamine receptor D1 are associated with heroin dependence but not impulsive behavior. Genet. Mol. Res. 14: 4041-4050.http://dx.doi.org/10.4238/2015. April.27.19

Maldonado R, Saiardi A, Valverde O, Samad TA, et al. (1997). Absence of opiate rewarding effects in mice lacking dopamine D2 receptors. Nature 388: 586-589. http://dx.doi.org/10.1038/41567

Meyers JL, Nyman E, Loukola A, Rose RJ, et al. (2013). The association between DRD2/ANKK1 and genetically informed measures of alcohol use and problems. Addict. Biol. 18: 523-536. http://dx.doi.org/10.1111/j.13691600.2012.00490.x

Moyer RA, Wang D, Papp AC, Smith RM, et al. (2011). Intronic polymorphisms affecting alternative splicing of human dopamine D2 receptor are associated with cocaine abuse. Neuropsychopharmacology 36: 753-762. http://dx.doi. org/10.1038/npp. 2010.208

Parsian A, Cloninger CR and Zhang ZH (2000). Functional variant in the DRD2 receptor promoter region and subtypes of alcoholism. Am. J. Med. Genet. 96: 407-411. http://dx.doi.org/10.1002/1096-8628(20000612)96:3<407::AIDAJMG32>3.0.CO;2-1

Prasad P, Ambekar A and Vaswani M (2010). Dopamine D2 receptor polymorphisms and susceptibility to alcohol dependence in Indian males: a preliminary study. BMC Med. Genet. 11: 24. http://dx.doi.org/10.1186/1471-2350-11-24

Rangel-Barajas C, Coronel I and Florán B (2015). Dopamine receptors and neurodegeneration. Aging Dis. 6: 349-368. http://dx.doi.org/10.14336/AD.2015.0330

Ritchie T and Noble EP (2003). Association of seven polymorphisms of the D2 dopamine receptor gene with brain receptor-binding characteristics. Neurochem. Res. 28: 73-82. http://dx.doi.org/10.1023/A:1021648128758

Rowlett JK, Platt DM, Yao WD and Spealman RD (2007). Modulation of heroin and cocaine self-administration by dopamine D1- and D2-like receptor agonists in rhesus monkeys. J. Pharmacol. Exp. Ther. 321: 1135-1143. http:// dx.doi.org/10.1124/jpet.107.120766

Teh LK, Izuddin AF, M H FH, Zakaria ZA, et al. (2012). Tridimensional personalities and polymorphism of dopamine D2 receptor among heroin addicts. Biol. Res. Nurs. 14: 188-196. http://dx.doi.org/10.1177/1099800411405030

Uhl GR, Drgon T, Johnson C, Fatusin OO, et al. (2008). "Higher order" addiction molecular genetics: convergent data from genome-wide association in humans and mice. Biochem. Pharmacol. 75: 98-111. http://dx.doi.org/10.1016/j. bcp.2007.06.042

van den Bree MB, Johnson EO, Neale MC and Pickens RW (1998). Genetic and environmental influences on drug use and abuse/dependence in male and female twins. Drug Alcohol Depend. 52: 231-241. http://dx.doi.org/10.1016/ $\underline{\mathrm{S} 0376-8716(98) 00101-X}$

Vereczkei A, Demetrovics Z, Szekely A, Sarkozy P, et al. (2013). Multivariate analysis of dopaminergic gene variants as risk factors of heroin dependence. PLoS One 8: e66592.http://dx.doi.org/10.1371/journal.pone.0066592

Wang GJ, Volkow ND, Fowler JS, Logan J, et al. (1997). Dopamine D2 receptor availability in opiate-dependent subjects before and after naloxone-precipitated withdrawal. Neuropsychopharmacology 16: 174-182. http://dx.doi. org/10.1016/S0893-133X(96)00184-4

Xu K, Lichtermann D, Lipsky RH, Franke P, et al. (2004). Association of specific haplotypes of D2 dopamine receptor gene with vulnerability to heroin dependence in 2 distinct populations. Arch. Gen. Psychiatry 61: 597-606. http:// dx.doi.org/10.1001/archpsyc.61.6.597

Zhang JP, Lencz T and Malhotra AK (2010). D2 receptor genetic variation and clinical response to antipsychotic drug treatment: a meta-analysis. Am. J. Psychiatry 167: 763-772.http://dx.doi.org/10.1176/appi.ajp.2009.09040598

Zhang Y, Bertolino A, Fazio L, Blasi G, et al. (2007). Polymorphisms in human dopamine D2 receptor gene affect gene expression, splicing, and neuronal activity during working memory. Proc. Natl. Acad. Sci. USA 104: 20552-20557. http://dx.doi.org/10.1073/pnas.0707106104

Genetics and Molecular Research 15 (4): gmr15048772 